\title{
INFLUENCE OF FILLING MEDIUM DENSITY POLYETHYLENE WITH VEGETABLE OILS ON FRICTION AND WEAR
}

\author{
K. H. Mahmoud ${ }^{1 *}$, M. I. Khashaba ${ }^{2}$ \\ ${ }^{1}$ Department of Mechanical, Al-Ameeria Integrated Technical Education Cluster, Cairo, Egypt \\ ${ }^{2}$ Department of Production Engineering and Mechanical design, Faculty of Engineering, Minia University, 61519 Minia, Egypt \\ * Correspondence: eng.khaledhma@ gmail.com; Tel: +201090001853; Fax: +20 86236674
}

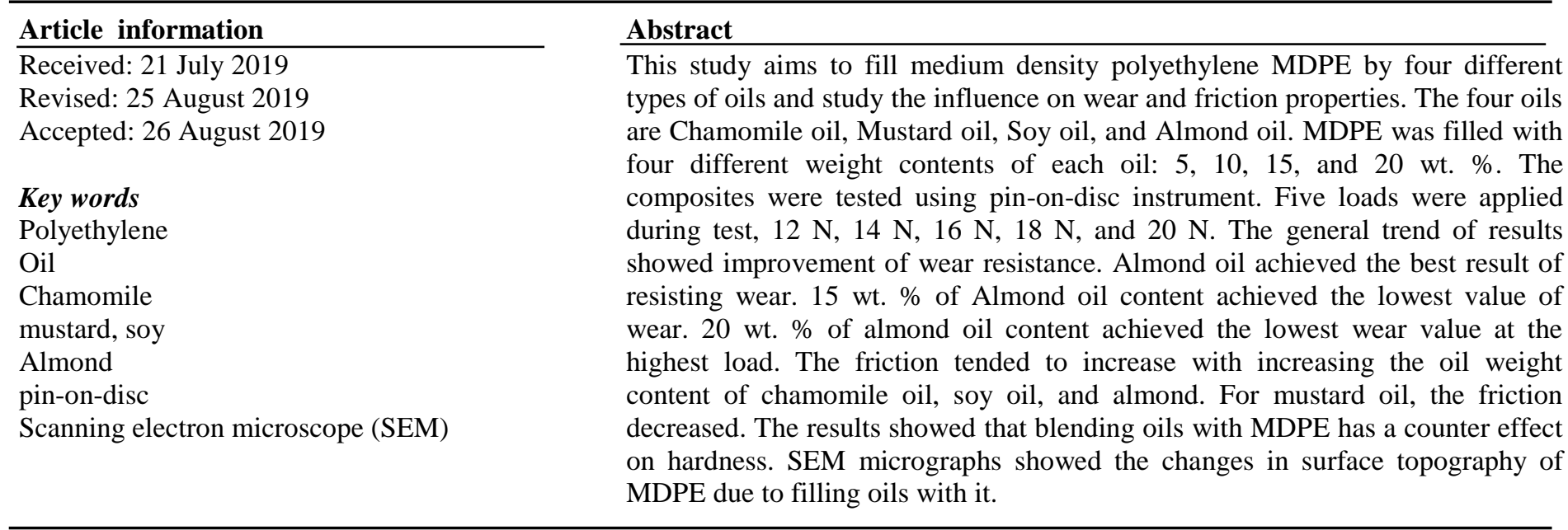

\section{Introduction}

Polyethylene $(\mathrm{PE})$ is polarized Ethylene $(\mathrm{CH} 2=\mathrm{CH} 2)$. Ethylene is the simplest olefin that may be polymerized through the action of initiators and catalysts, [1].

Polyethylene PE is widely used in many different industrial and medical applications. PE exhibits good resistance against biological attack, [2]. For example, Ultra-high Molecular Weight Polyethylene UHMWPE is used for manufacturing of components of artificial replacement joints "prosthesis joints". Low Density Polyethylene LDPE is used for manufacturing of some types of cable insulations and pipes. High Density Polyethylene HDPE and Medium Density Polyethylene MDPE are used for manufacturing of bottles of domestic applications, grocery sacks, cable insulations, pipes etc.

UHMWPE, HDPE, and MDPE have long linear molecular chains, but UHMWPE have chains longer than HDPE and MDPE. So the molecular weight of UHMWPE is greater than molecular weight of HDPE AND MDPE. The molecular weight affects the degree of crystallinity which can be achieved within a material, [3].

The blends of polyphenylene oxide/ultrahigh molecular weight polyethylene-g-polystyrene/ultrahigh molecular weight polyethylene were prepared by $\mathrm{Wu}$, Qian et al. The wear test was conducted then they found that blend of 90/10/0, compared with other ratios, was the optimum ratio which achieved the lowest wear rate and friction coefficient, [4].

One of attempts, to improve tribological behaviors, was by lubricating the surface of test with paraffin and vegetable oils such as almond, castor, corn, glycerine, jasmine, olive and sun flower oils were used as lubricants in presence of magnetic field and then pin-on-disc test has been applied. The test using lubricated disc resulted wear and friction lower than this dry one, [5].

Improving of the frictional properties of injection moulded thermoplastics using tribological additives were studied by J. L.Laursen et al. They studied influence of tribological additives, polydimethylsiloxane and polytetrafluoroethylene (PTFE), on friction and impact properties of polyacetal (polyoxymethylene). The test were conducted through ring-on-disc testing against polypropylene (PP) to simulate use-conditions in a particular medical device. It was found that additives effectively reduced the friction, [6].

Blending some types of polymers with each other may achieve good mechanical and tribological behaviors. $M$. Palabiyik and S. Bahadur studied the mechanical and tribological behaviors of polyamide 6 (PA6) and HDPE polyblends made using maleic anhyride polypropylene PP as the compatibilizing agent. The compositions investigated for tribological behavior were $80 \mathrm{wt}$ \% PA6-20 wt.\% HDPE and 60 wt.\% PA6-40 wt.\% HDPE. They reinforced polyblends with glass fiber (GF) and filled with PTFE and copper oxide $(\mathrm{CuO})$ The minimum wear and friction coefficient were obtained at blending of $10 \%$ wt. PTFE, [7].

Michel Wathier et al. created a polymer acts as a lubricant in the human joints. The polyanion, sodium poly (7oxanorbornene-2-carboxylate), is synthesized by ring-opening metathesis polymerization of methyl 5-oxanorbornene-2carboxylate. When dissolved in aqueous solution and applied to the surface of human cartilage it reduces the friction at the 
interface and acts as a lubricant. The advantage of this polymer created remains in the joint for more than two weeks whereas leading synovial fluid supplement may last one or two days, [8].

An old attempt to reduce the wear of UHMWPE in total joint replacements was through Crosslinking of UHMWPE by ionizing radiation. This attempt was based upon the theory of orientation softening, [9].

Blending some oils with a polymer can produce a selflubricating bearing material. Vegetable oils are much recommended for this purpose. Vegetable oils are good lubricants due to its amphiphilic properties. The amphiphilic properties resulted from the fatty acid composition of vegetable oils contribute to a better lubricity and effectiveness as antiwear compounds than mineral or synthetic lubricant oils. However, limited viscosities of these oils constrain the use of them in many industrial application, [10]. So the addition of some chemical additions (like ethylene-vinyl acetate copolymer (EVA)) to vegetable oils (like soy oil) can increase their viscosities and improve their tribological properties, L. Quinchia et al. reported [10], or blending these oils with bearing materials to be self-lubricated "as discused in this search".

This study aims to blending four different types with PE to act self-lubricating to improve wear and friction properties of MDPE. As mentioned, PE has a wide use in medical application especially artificial joints. Most of vegetable oils, including oils used in the search, are safe to human use whether liquid or solid state (polymerized).

Vegetable-oil-based polymers, like polyurethane, have excellent biocompatibilities with unique properties, [11].

Four oils were chosen to examine their validity to create self-lubricated bearing material.

PE and the four oils which are studied in this search are safe to human use. So the composite of them can be classified as a biobearing material.

The four oils are, almond oil, soy oil, mustard oil, and chamomile oil.

Smoke point of almond oil is about $221{ }^{\circ} \mathrm{C}$ and $232{ }^{\circ} \mathrm{C}$ for Soy oil. Mustard oil smoke point is in range from $210{ }^{\circ} \mathrm{C}$ to 250 ${ }^{\circ} \mathrm{C}$. [12]. Chamomile oil is affecting by heating above $200{ }^{\circ} \mathrm{C}$ [13].

Almond oil composes of different chemical compounds and elements. It consists of minerals, e.g. calcium, copper, iron, and sodium; phytosterol, e.g. campesterol, clerosterol, stigmasterol; vitamins; fatty acids, e.g. linoleic, oleic, Palmitic; and protein and amino acids.

The fatty acid profile is one of the highest that affect the oil oxidation process. The oleic acid/linoleic acid ratio $(\mathrm{O} / \mathrm{L})$ in almond oil has index of resistance to oil rancidity better than other nut species, like hazelnut, the criterion adopted has been the ratio of unsaturated fatty acids/saturated fatty acids [14]. As a result, almond oil achieves the best results among other oils. It resisted oxidation, and consequently degradation, due to temperature and pressure of test.

This result has been emphasized by A. E. Delgado-Tobón et al. The search compared two mineral oils, have contrasting viscosity and no additives, with almond oil. The instrument test was four-ball tribometer. It was found almond oil has greater lubricity than the two mineral oils. Almond oil showed better performance under extreme pressure conditions and a greater weld point than mineral oils. An FTIR spectroscopic analysis determined that, under the conditions of the current tests, almond oil does not oxidize, [15].

Medically, almond oil has good pharmaceutical properties .Through clinical experiences it was found that almond oil acts on reducing hypertrophic scarring post-operatively. It can smooth and rejuvenates skin, [16]. Also almond oil has good benefits for general human health due to its chemical constituents, [14].

Soy oil is compound of vitamins (Vitamin E "alphatocopherol" and Vitamin K "phylloquinone") and fatty acids (saturated Fatty acids, monounsaturated Fatty acids, polyunsaturated Fatty acids) in different percentages, [17].

Soy oil has good health impact due to its many chemical compounds which consists of. For example, $\alpha$-linolenic acid, in soy oil, is useful for those suffer from some heart diseases, [18].

Also Isoflavones in soy are believed to have preventive effects for several hormone-dependent diseases, [19].

The main components of the chamomile oil are: chamazulene and its precursor matricin, bisabolols and bisabolol oxides, trans- $\beta$-farnesene, cis- and trans-isomers of the spiroethers, (13). Essential oils (e.g. chamomile oil) can be a useful for non-medicinal option or can also be combined with conventional care for some health conditions, provided safety and quality issues are considered, [20]. Chamomile oil is used in many industries (food, cosmetics, and Pharmaceutical products).

Mustard oil is compound of many fatty acids (saturated Fatty acids, monounsaturated Fatty acids, polyunsaturated Fatty acids) in different percentages [21]. The main chemical compound of mustard oil is Allyl isothiocyanate $(\mathrm{CH} 2=\mathrm{CHCH} 2 \mathrm{~N}=\mathrm{C}=\mathrm{S})$, [22]. Mustard oil has high levels of both alpha-linolenic acid and Erucic acid. Available studies conducted are different. Many of them have revealed that no negative health effects of any exposure to Erucic acid have been documented in humans, whereas others have suspicions about affecting of this acid on human health. So more studies are required to clearly determine likely harms of this acid when touch to human tissue directly, [23].

\section{Experimental}

\section{Materials and Compositions}

Material used is Medium Density Polyethylene (MDPE) with four different types of commercial oils (see Table1). MDPE (supplied by Ethydco Egypt, code: EM-3405-UVH) has the following characteristics: $0.934 \mathrm{~g} / \mathrm{cm}^{3}$ density, $\left(190{ }^{\circ} \mathrm{C} / 2.16\right.$ $\mathrm{Kg}) 5.0 \mathrm{~g} / 10 \mathrm{~min}$ melt index, $14 \mathrm{MPa}$ yield strength.

The four oils are almond oil, soy oil, mustard oil, and chamomile oil. The compositions of MDPE with the four oils were as shown in (Table 1). 
Table 1: Composition of MDPE with the four types of oils

\begin{tabular}{ccccc}
\hline $\begin{array}{c}\text { Polyethylene } \\
\text { PE\% }\end{array}$ & $\begin{array}{c}\text { almond } \\
\text { oil \% }\end{array}$ & $\begin{array}{c}\text { chamomile } \\
\text { oil \% }\end{array}$ & $\begin{array}{c}\text { soy oil } \\
\text { \% }\end{array}$ & $\begin{array}{c}\text { mustard } \\
\text { oil \% }\end{array}$ \\
\hline 100 & - & - & - & - \\
95 & 5 & 5 & 5 & 5 \\
90 & 10 & 10 & 10 & 10 \\
85 & 15 & 15 & 15 & 15 \\
80 & 20 & 20 & 20 & 20 \\
\hline
\end{tabular}

\section{Composites Preparation}

Composites were produced using a hot compresses mold as shown in (Figure 2.1). A pressure of about $2 \mathrm{MPa}$ was applied see (Figure 2.1). Different loadings of oil, for each oil, were mixed homogeneously with MDPE using a turbine mixer. Specimen were heated by $180 \sim 190{ }^{\circ} \mathrm{C}$ for $8 \mathrm{~min}$ with continuous pressing. The mold was cooled in water at about 18 ${ }^{\circ} \mathrm{C}$. (Figure 2.2) shows specimens after getting out of the mold.

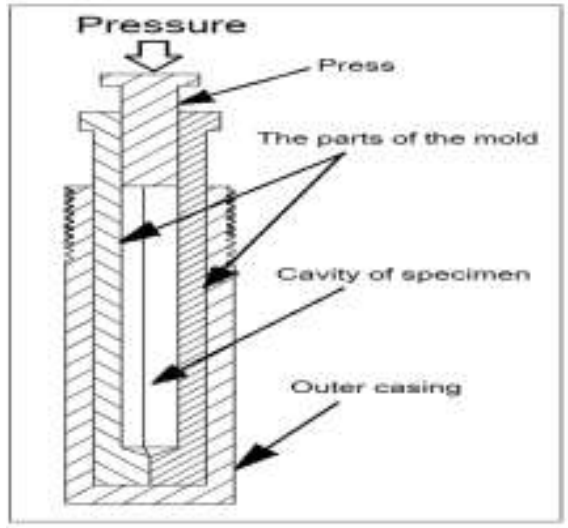

Figure 2.1: The compressed mold
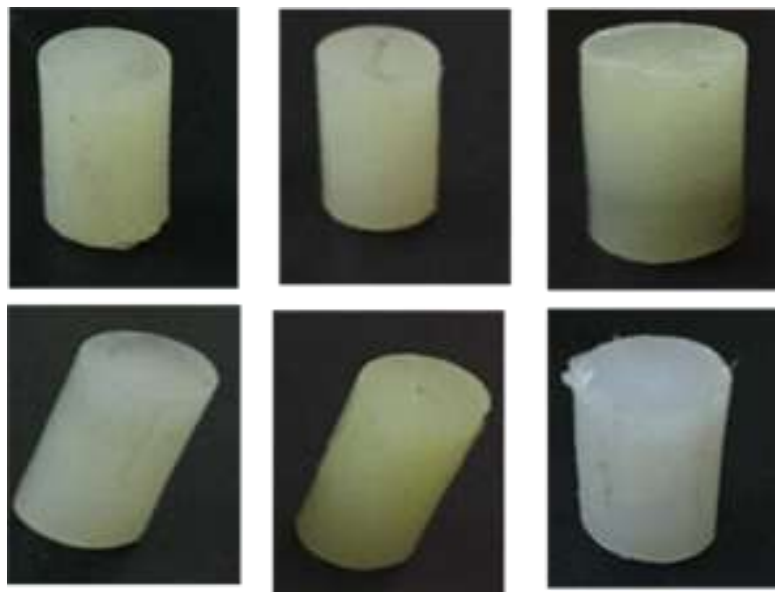

Figure 2.2: Test specimens

\section{Experimental Work}

Tribological Test was done according to ASTM G99 method using pin-on-disc instrument tester (Figure 2.3). The disc dimensions are: $4 \mathrm{~mm}$ thickness and $150 \mathrm{~mm}$ outer diameter.
The track diameter is $75 \mathrm{~mm}$. As mentioned, dimensions of pin (polymer specimen) are: $30 \mathrm{~mm}$ length and $8 \mathrm{~mm}$ diameter. The material of disc is a polished stainless steel 316 . The rotation speed disc was $250 \mathrm{rpm}$. Each tests were carried out for 7 minutesunder laboratory conditions $\left(\sim 22^{\circ} \mathrm{C}\right.$ and $\sim 10 \%$ humidity).

The weight loss "wear" was determined by the following equation:

$$
\text { wear }=m_{b}-m_{a}
$$

where $m_{b}$ is mass of specimen before test and $m_{a}$ is mass of specimen after test. The mass was weighed by a sensitive balance (readability: $0.1 \mathrm{mg}$, capacity $200 \mathrm{~g}$, supplied by YMC Co., Ltd, Japan) show in (Figure 2.4).

The dynamic friction coefficient $\mu_{\mathrm{d}}$ was determined using the following equation:

$$
\mu_{d}=\frac{F_{d}}{F_{n}}
$$

where $F_{d}$ is the frictional dynamic force, and $F_{n}$ is the normal force. There were five loads used as a normal force: 12, 14, 16, 18 , and $20 \mathrm{~N}$. These loads were applied with each oil weight content.

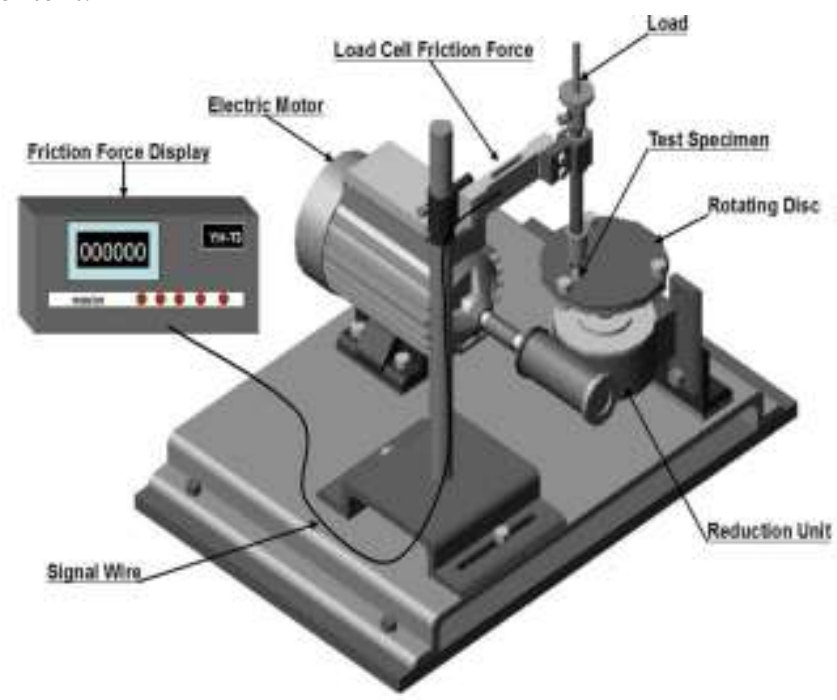

Figure 2.3: Pin-on-disc instrument tester

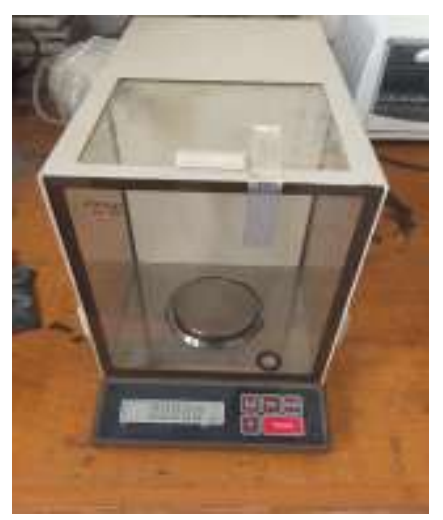

Figure 2.4: A sensitive balance

\section{Test specimens}

Specimens of each composition were prepared in dimension of $30 \mathrm{~cm}$ length and $8 \mathrm{~mm}$ diameter. For every composition, three specimens were tested and the average of the three was reported. 


\section{Hardness Test}

The hardness test was conducted according to the ASTM D2240 method with shore D hardness tester (Figure 2.5). The hardness test was conducted on three different positions on specimen worn surface. See (Figure 2.6)

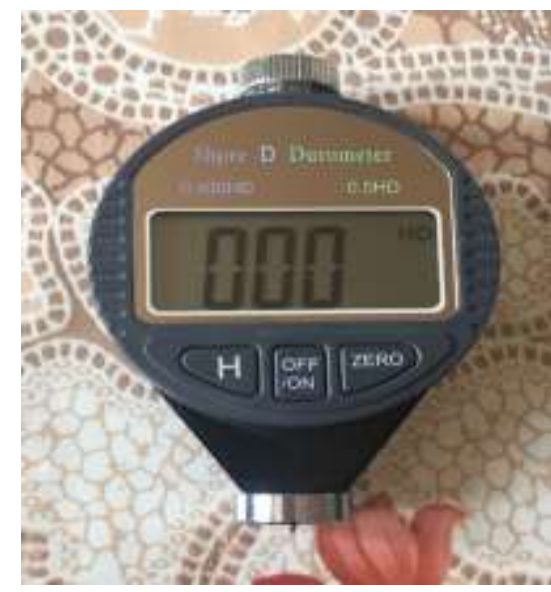

Figure 2.5: Shore D hardness

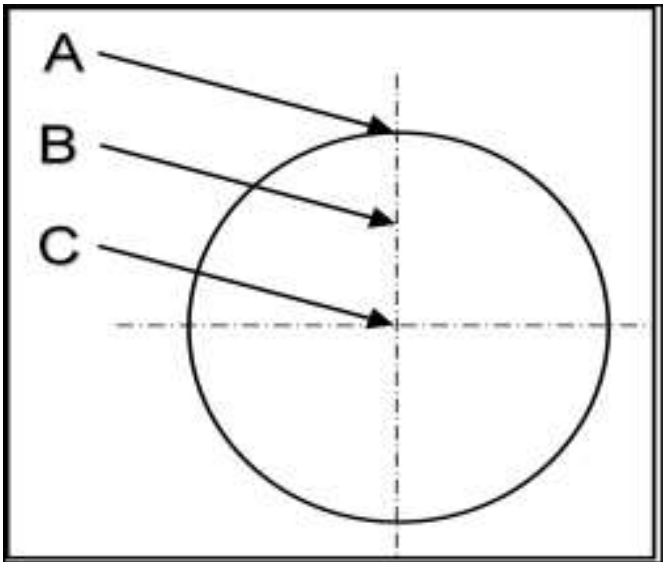

Figure 2.6: The positions where hardness measured

\section{SEM Microscopy}

The worn surface was coated by a very thin layer of Gold using Magnetron Sputtering Coater instrument see (Figure 2.7). This is called "sputtering process". This process aims to prevent electrical charging on the surface of specimen. After that, the surface was scanned by a Scanning Electron Microscope SEM (JSM-IT200, Japan) at acceleration voltage of $5.0 \mathrm{KV}$.

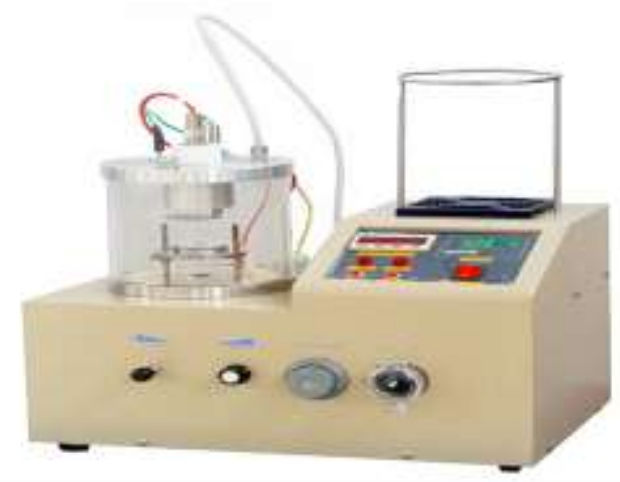

Figure 2.7: Magnetron Sputtering Coater

\section{Results and Discussion}

\section{Tribological Properties}

The influence of chamomile oil content on wear and friction coefficient at different loads is shown in (Figure 3.1). The results show that: the wear trend tends to decrease with increasing load for most of oil weight contents. Generally, the friction coefficient of MDPE filled with different oil contents is still greater than pure MDPE one. However, the friction coefficient trend decays with increasing loads.

The influence of mustard oil content on wear and friction coefficient at different loads is shown in (Figure 3.2). The friction coefficient trend behaves to down at low loads. It again rises gradually with increasing the load. The wear gradually decreases with increasing the load to achieve the lowest value at the highest load at all oil weight contents.

The influence of soy oil content on wear and friction coefficient at different loads is shown in (Figure 3.3). The wear tends to slightly decrease at low loads whereas it obviously decreases at high loads. The friction coefficient decreases with increasing load for each oil weight content.

The influence of almond oil content on wear and friction coefficient at different loads is shown in (Figure 3.4). The results show that: wear obviously decreases with increasing oil content at all loads. It can be obtained that it significantly decreases with increasing the oil weight content at the highest load. Friction coefficient increases gradually with increasing both load and oil weight content.

\section{Hardness properties}

As shown in (Figure 3.5), the hardness of MDPE filled with different oils decreases with increasing oil content. It seems that a new compound of polymer and oil can affect bonding of polymer matrix.

\section{Micrographical Properties}

Indeed investigation of morphology of composite material can interpret its behaving. It also provides the mechanical properties desired. SEM micrographs showed the morphology of worn surface and the direction of wear. The direction of wear can be clearly seen in (Figure 3.7, Figure 3.8.a, Figure 3.9, Figure 3.10.a, and Figure 3.11.a). The direction of wear is pointed to by arrows.

Oluyemi O. Daramola et al. (24) reported that composites change the morphology of PE and consequently change the surface properties. SEM micrographs reported that the surface of pure MDPE (Figure 3.7) seems relatively smoother than MDPE filled with different oils. Surface topography of MDPE filled with different oils see (Figure 3.8, Figure 3.9, Figure 3.10, and Figure 3.11) shows a clear increasing in asperities in terms of number and shape. This means reducing true contact area. As a result, the wear reduces. This result was emphasized by the wear test conducted.

The transfer film produced due to wear plays a key role in wear resistance. SEM micrographs show the shape and size of 

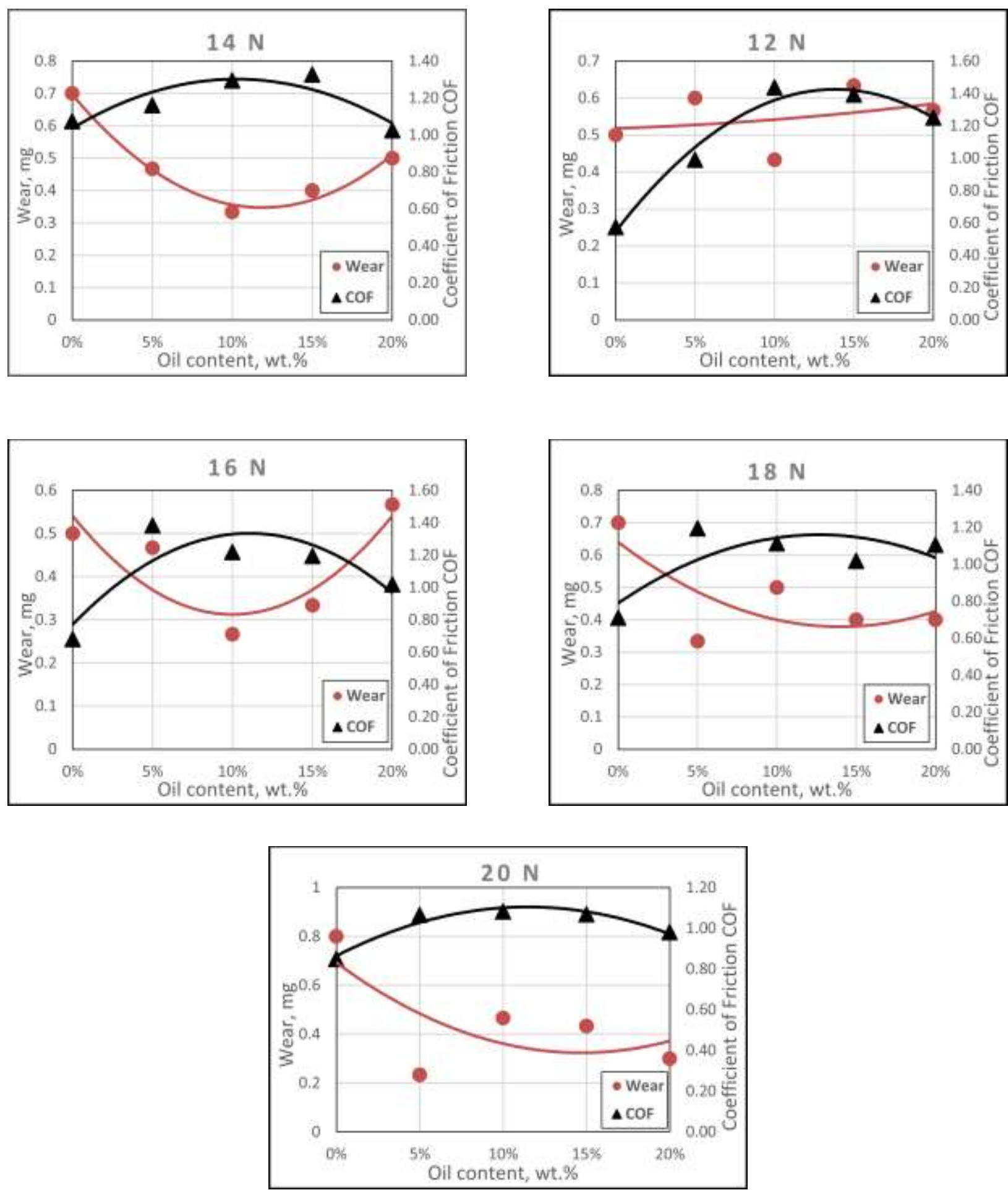

Figure 3.1: Wear and friction coefficient versus chamomile oil content 

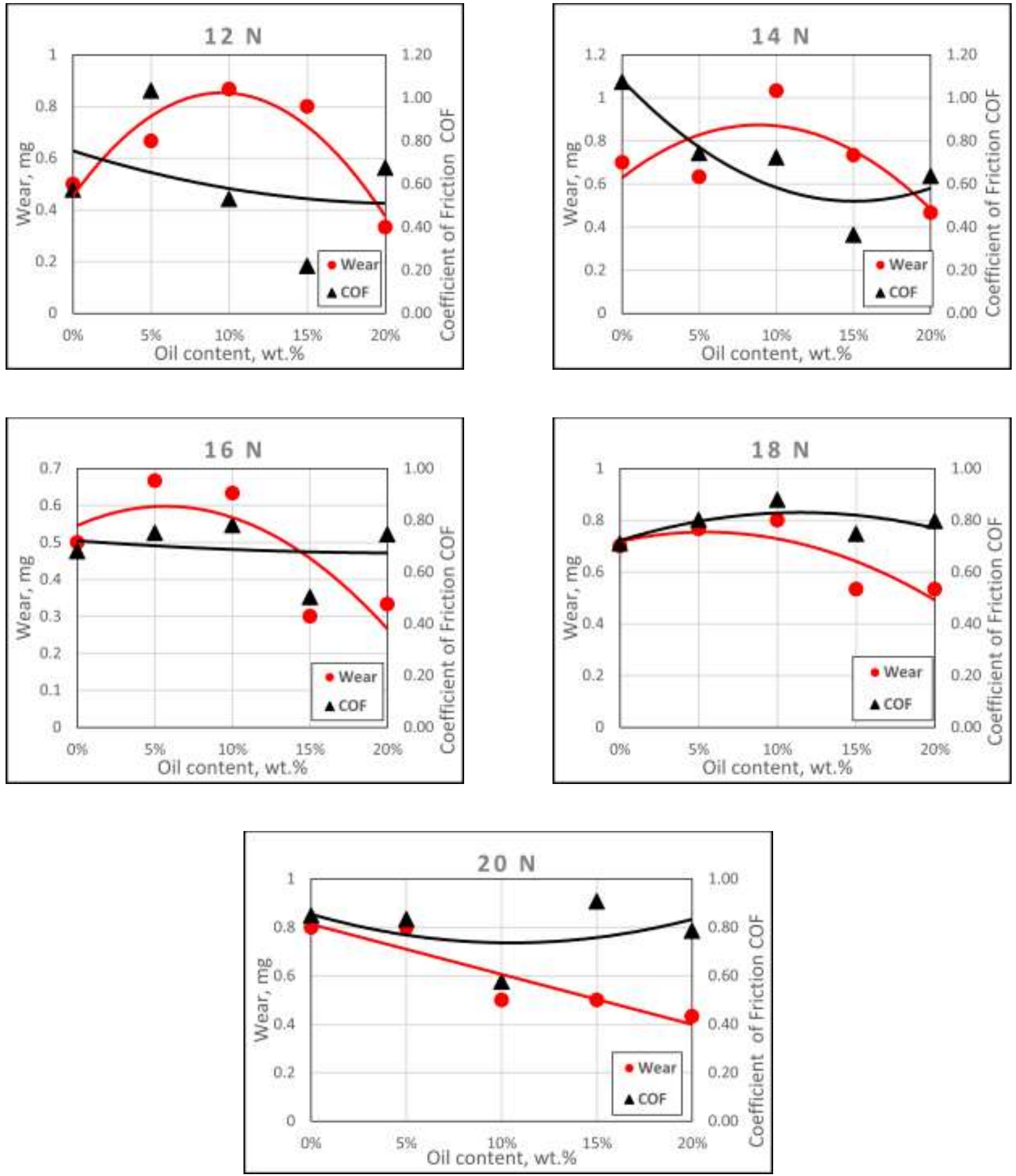

Figure 3.2: Wear and friction coefficient versus mustard oil content 

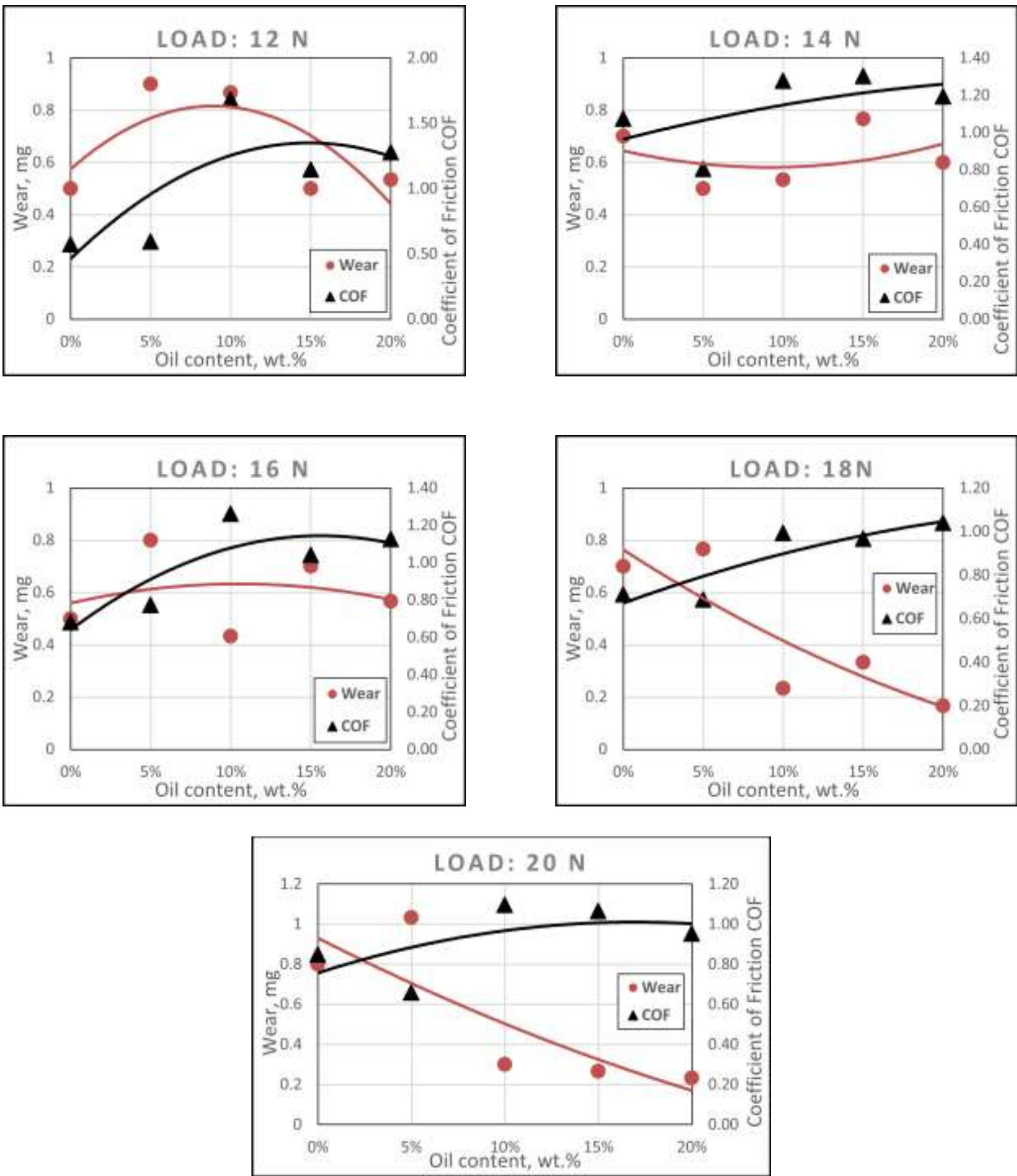

Figure 3.3: Wear and friction coefficient versus soy oil content 

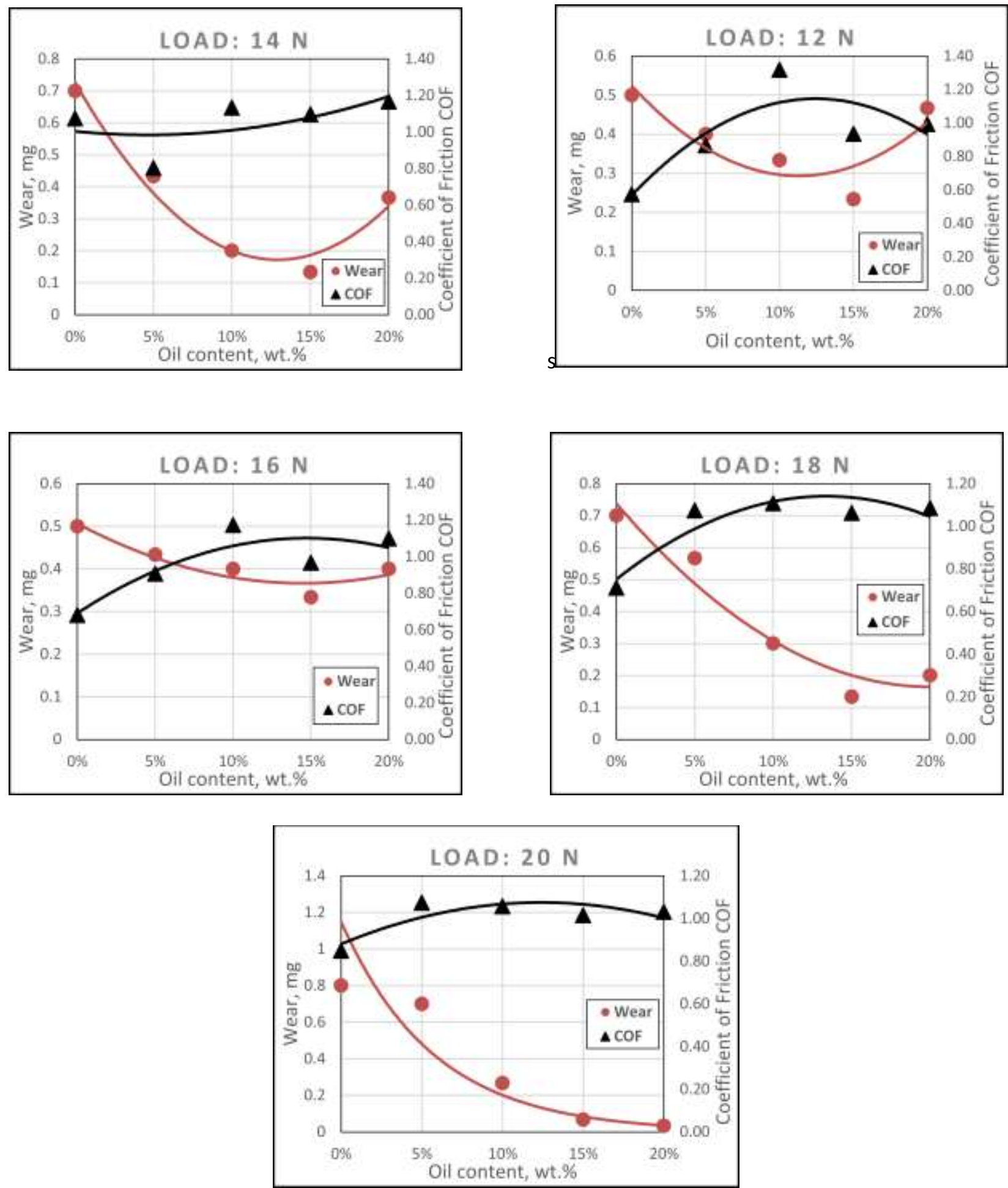

Figure 3.4: Wear and friction coefficient versus almond oil content 


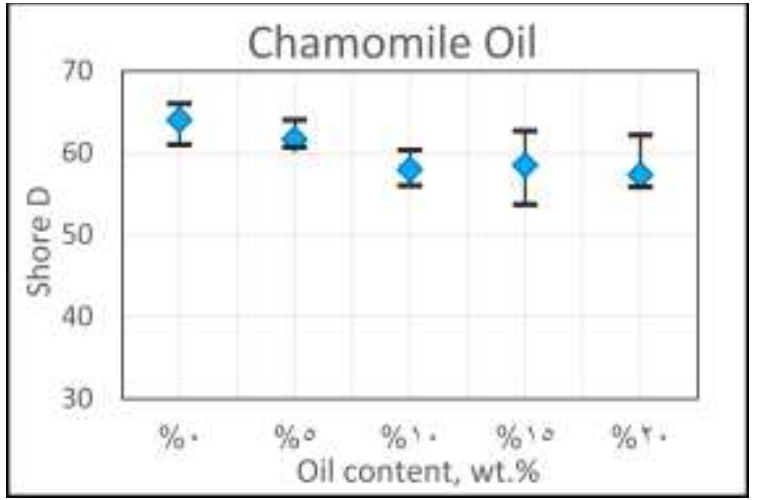

(a)

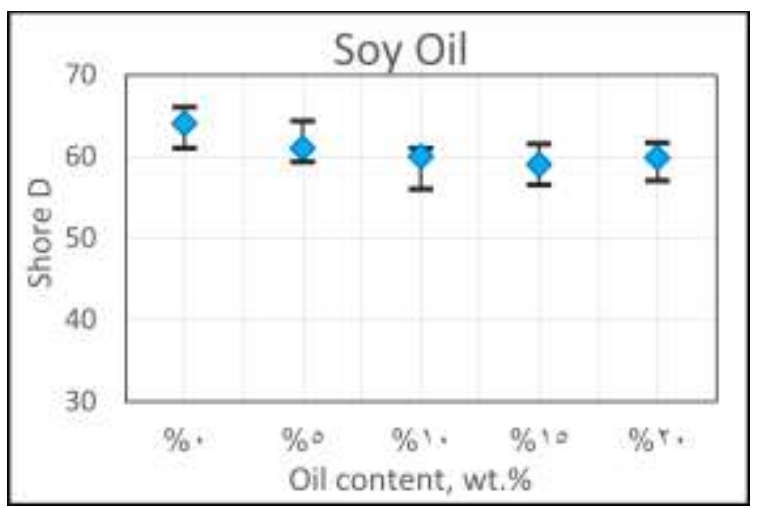

(c)

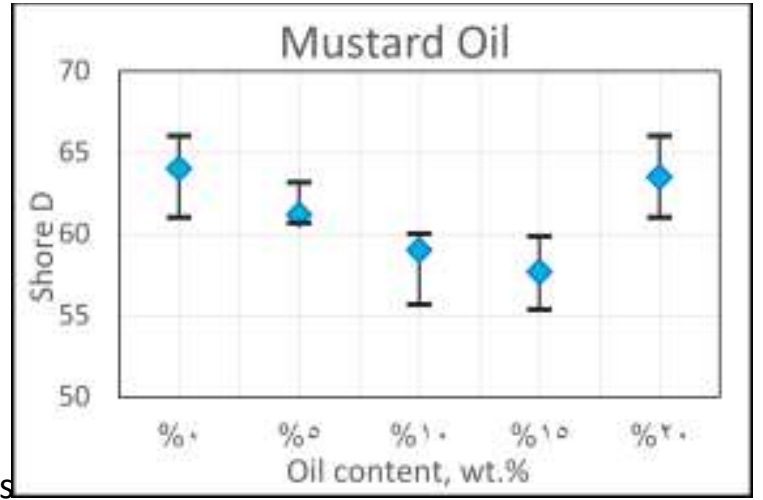

(b)

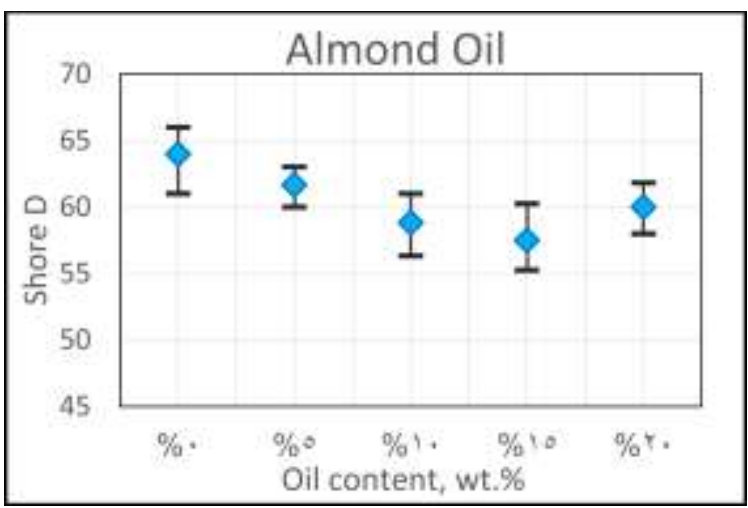

(d)

Figure 3.5 The hardness shore D of MDPE filled with different contents of oils: (a) Chamomile oil (b) Mustard oil (c) Soy oil (d) Almond oil.

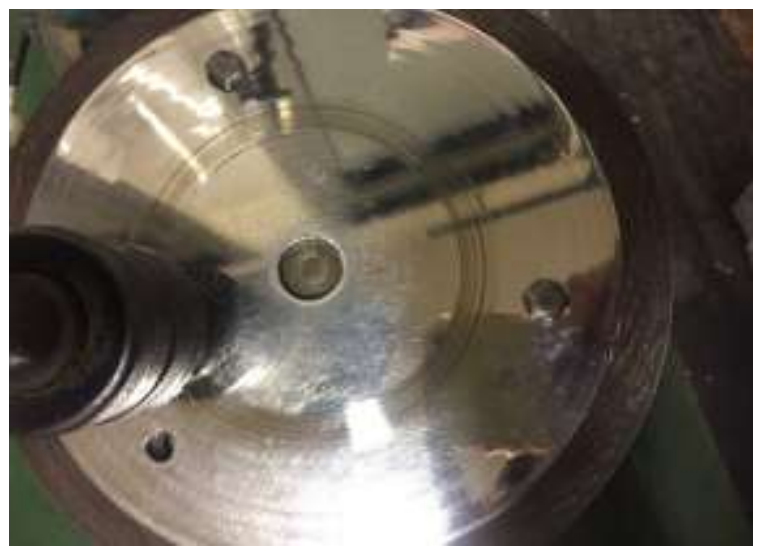

Figure 3.6: Friction disc

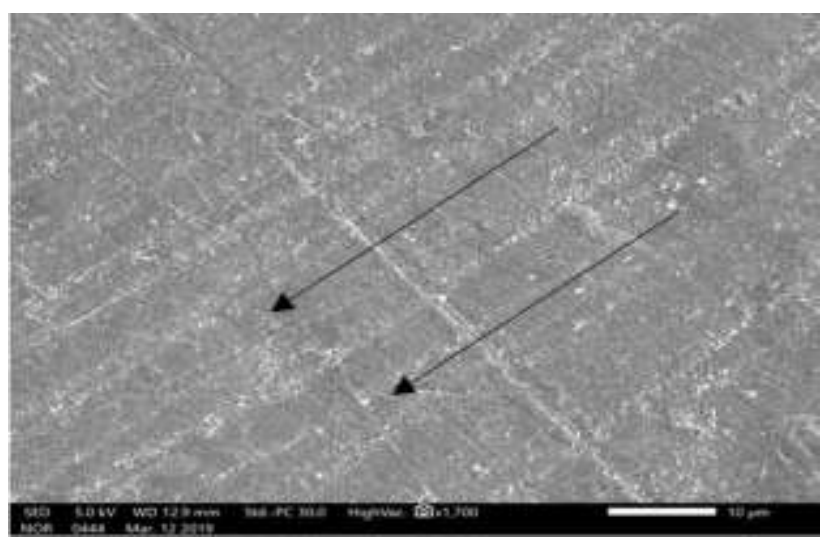

Figure 3.7: SEM micrograph of pure MDPE 

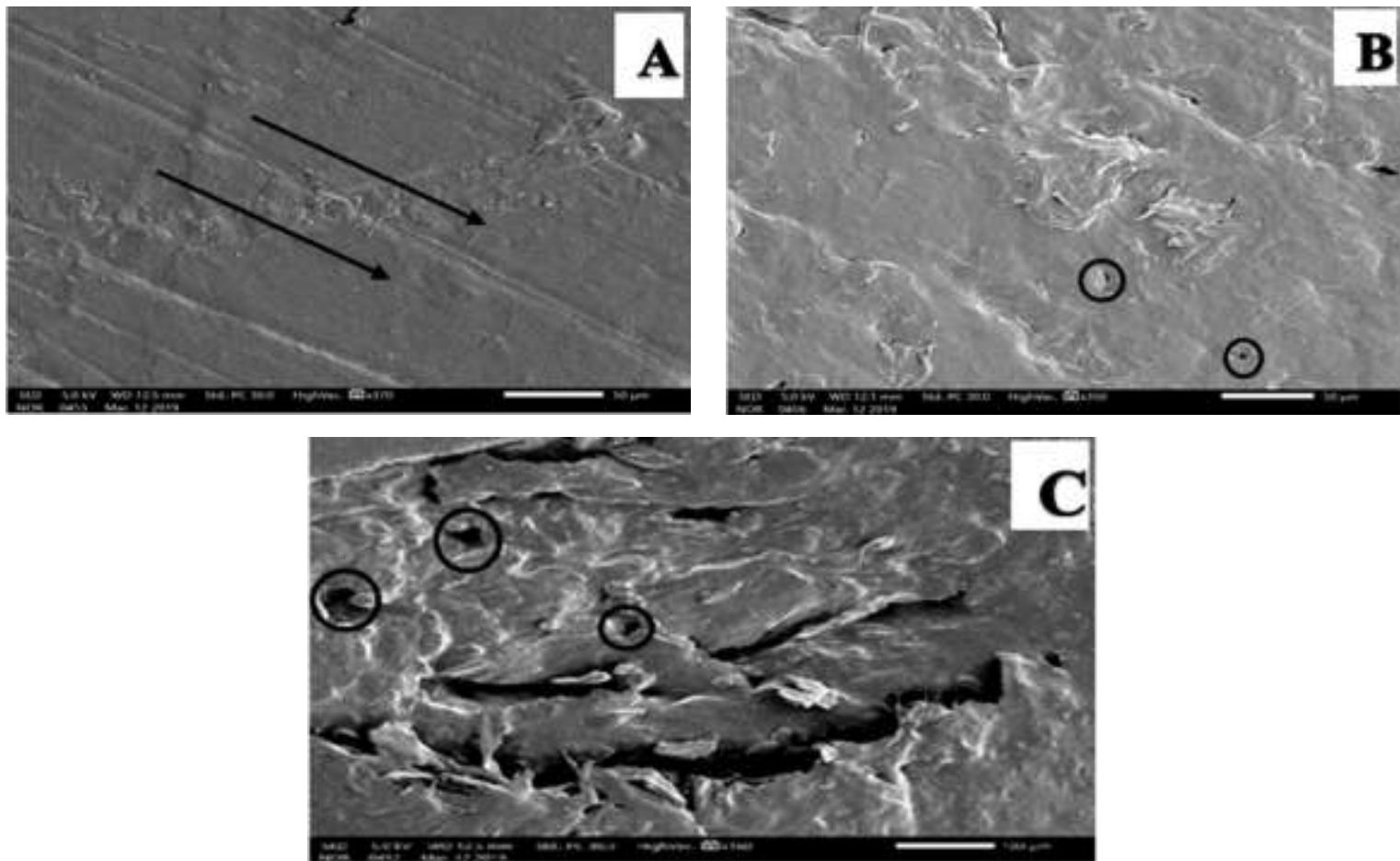

Figure 3.8: SEM micrograph of MDPE filled with chamomile oil
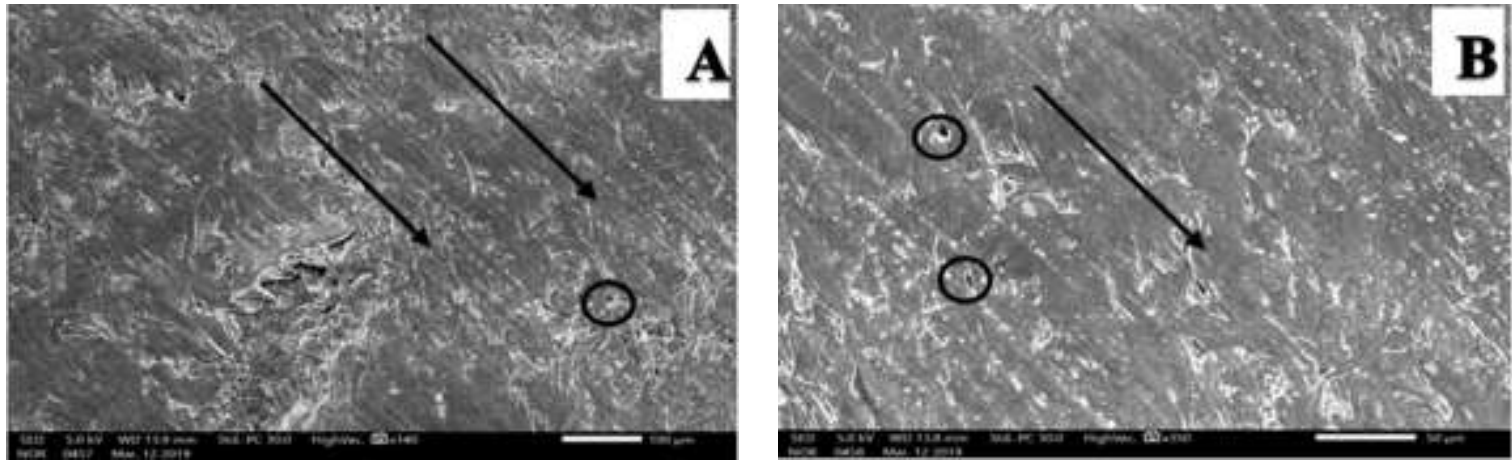

Figure 3.9: SEM micrograph of MDPE blended with mustard oil
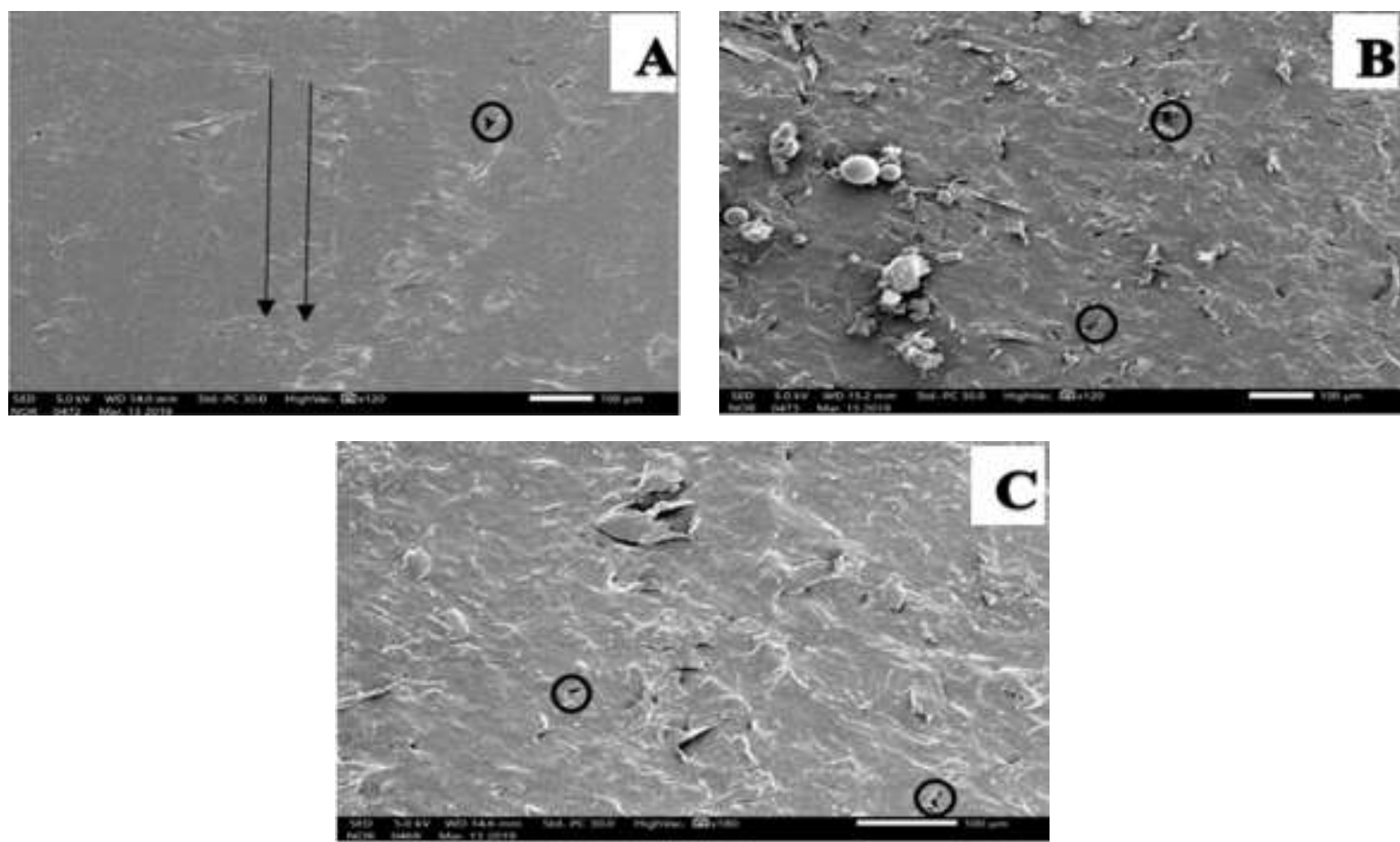

Figure 3.10: SEM micrograph of MDPE filled with Soy oil 

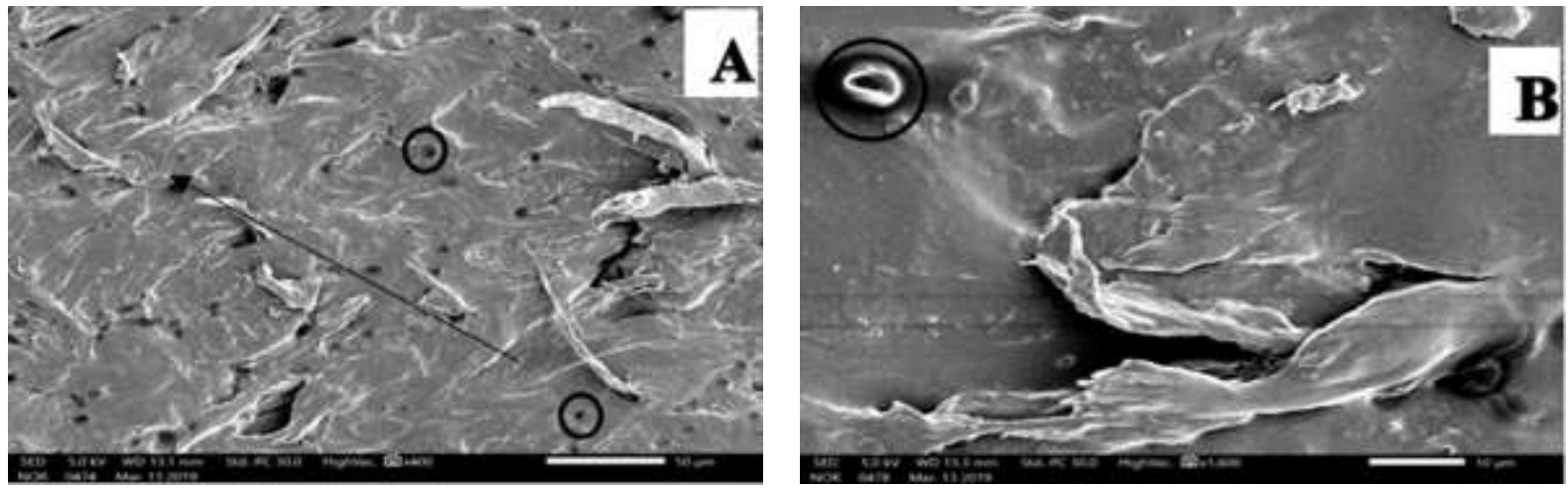

Figure 3.11: SEM micrograph of MDPE filled with almond oil

worn particles which are forming a part of the transfer film produced. The cavities shown on surface of specimens can interpret how the oil observed on the disc was preserved. These cavities were containers for this oil. (Figure 3.6) indicates a visible thin transfer film (pointed to by the arrows) of oil and some worn particles resulted from wear on the disc. The scenario supposed may be that: pressure on the specimen resulted adsorbing oil preserved in cavities through the polymer matrix. The worn surface of pure MDPE produced due to friction seems different from this of MDPE oil filled. Comparing SEM micrograph of pure MDPE (Figure 3.7) to micrographs of MDPE oil filled would show that plastic deformation of MDPE-almond oil filled is higher than pure MDPE.

\section{Conclusions}

1. From results of chamomile oil, it can be concluded that 10 wt. \% oil content can be sufficient for low and medium load applications whereas $5 \mathrm{wt}$. \% is suitable for high load applications to achieve the lowest wear.

2. The results of mustard oil show that $20 \mathrm{wt}$. $\%$ oil content can be sufficient for different applying loads to achieve lower wear.

3. The results of soy oil point out that $5 \mathrm{wt}$. $\%$ oil weight content may sufficient for medium loads where $20 \mathrm{wt} \%$ oil weight content could be sufficient for high loads in order to obtain the lowest wear at these loads.

4. The results of almond oil point out that $15 \mathrm{wt} \%$ oil weight content is for different loads considering that $20 \mathrm{wt}$. $\%$ can be much better for high loads to achieve lower wear.

5. Comparing to other oils studied in this search, almond oil is the most appropriate one to resist the wear. The results concluded that $15 \mathrm{wt}$. \% oil weight content achieved the lowest wear at different loads noting that 20 wt. \% oil weight content is highly recommended for high loads. Oil weight content of $20 \mathrm{wt}$. \% achieved about $0.07 \mathrm{mg}$ at 20 $\mathrm{N}$ under the test conditions.

6. Blending MDPE with oils lead to decrease the hardness. The results showed that increasing oil content has a counter effect on hardness of MDPE. The hardness of MDPE decreases with increasing the oil content. Almost filling MDPE with the four oils produced this result.

\section{References}

[1] Malpass DB. Introduction to Industrial Polyethylene Canada: Scrivener Wiley; 2010.

[2] Chanda M, Roy SK. Plastics Fundamentals Properties, and Testing. USA: Taylor \& Francis group; 2009.

[3] Visakh PM, Morlanes MJM. Polyethylene-Based Blends, Composites and Nanocomposites. USA: Scrivener Publishing; 2015

[4] Wu Q, Li W, Zhang J, Yao Z. Tribological, Mechanical Properties, and Morphology of Polyphenylene Oxide/Ultrahigh Molecular Weight Polyethylene Blends. Polymer-Plastics Technology and Engineering. 2017;56(5):535-42.

[5] Abdel-Jaber G, Mohamed M, Ali WY. Effect of Magnetic Field on The Friction and Wear of Polyamide Sliding Against Steel. Materials Sciences and Applications. 2014;5(01):46.

[6] Laursen JL, Sivebæk IM, Christoffersen L, Papsøe M, Vigild ME, Brondsted $\mathrm{P}$, et al. Influence of Tribological Additives on Friction and Impact Performance of Injection Moulded Polyacetal. Wear. 2009;267(12):2294-302.

[7] Palabiyik M, Bahadur S. Tribological Studies of Polyamide 6 and Highdensity Polyethylene Blends Filled with PTFE and Copper Oxide and Reinforced with Short Glass Fibers. Wear. 2002;253(3-4):369-76.

[8] Wathier M, Lakin BA, Bansal PN, Stoddart SS, Snyder BD, Grinstaff MW. A Large-Molecular-Weight Polyanion, Synthesized via Ring-Opening Metathesis Polymerization, as a Lubricant for Human Articular Cartilage. Journal of the American Chemical Society. 2013;135(13):4930-3.

[9] Wang A, Essner A, Polineni V, Stark C, Dumbleton J. Lubrication and Wear of Ultra-high Molecular Weight Polyethylene in Total Joint Replacements. Tribology International. 1998;31(1-3):17-33.

[10] Quinchia L, Delgado M, Reddyhoff T, Gallegos C, Spikes H. Tribological Studies of Potential Vegetable Oil-based Lubricants Containing Environmentally Friendly Viscosity Modifiers. Tribology International. 2014;69:110-7.

[11] Miao S, Wang P, Su Z, Zhang S. Vegetable-oil-based Polymers as Future Polymeric Biomaterials. Acta biomaterialia. 2014;10(4):1692-704

[12] Marcus JB. Culinary Nutrition: The Science and Practice of Healthy Cooking: Academic Press; 2013.

[13] Franke R, Schilcher H. Chamomile: Industrial Profiles: CRC Press, Taylor \& Francis Group; 2005

[14] Company RSi, Gradziel TM. Almonds: Botany, Production and Uses. CAB International; 2017. p. 428-48.

[15] Delgado-Tobón AE, Aperador-Chaparro WA, García-Cáceres RG Evaluation of The Lubricating Power of Sweet Almond Oil Without Additives Evaluación del poder lubricante de aceite de almendras dulces sin aditivos. 2018;85(205):179-83.

[16] Ahmad Z. The Uses and Properties of Almond Oil. Complementary Therapies in Clinical Practice. 2010;16(1):10-2.

[17] Soy Oil. USA: USDA National Nutrient, 04583; 2018 [online] www.nal.usda.gov.

[18] Connor WE. $\alpha$-Linolenic Acid in Health and Disease. The American Journal of Clinical Nutrition. 1999;69(5):827-8.

[19] Choi M-S, Rhee KC. Production and Processing of Soybeans and Nutrition and Safety of Isoflavone and Other Soy Products for Human Health. Journal of Medicinal Food. March 31, 2006;9(1).

[20] Ali B, Al-Wabel NA, Shams S, Ahamad A, Khan SA, Anwar F. Essential Oils Used in Aromatherapy: A Systemic Review. Asian Pac J Trop Biomed. 2015;5(8):601-11.

[21] Mustard Oil. USA: USDA National Nutrient, 04583; 2018 [online] www.nal.usda.gov.

[22] Jordt S, Bautista DM, Chuang H, McKemy DD, Zygmunt PM, Högestät ED, et al. Mustard Oils and Cannabinoids Excite Sensory Nerve Fibres Through the TRP Channel ANKTM1. Nature. 2004;427(6971):260-5. 
[23] Erucic Acid in Food: A Toxicological Review and Risk Assessment. Australia and Nwe Zealand, : Food Standards Australia New Zealand (FSAN), 2003.

[24] Oluyemi O. Daramola, Okikiola G. Agbabiaka, Isiaka O. Oladele, Marindoti DM. Influence of Silica Sand Particles on The Tensile Properties and

Water Absorption Behaviour of High Density Polyethylene Matrix Composites. ANNALS of Faculty Engineering Hunedoara - International Journal of Engineering. 2016;14. 